\title{
Regional Policy from a Supra-Regional Perspective
}

\author{
Ugo Fratesi* \\ 24th November 2005
}

\section{JEL Codes:}

R13, R58, H79 E61

Keywords: Regional Policy, Agglomeration Economies, National Efficiency, Interregional Equity.

*Politecnico di Milano, Piazza Leonardo da Vinci, 32, 20133 Milan, Italy. Telephone:+39-(0)2-2399-3966. Fax: +39-(0)2-2399-2710. E-mail: ugo.fratesi@polimi.it. 


\section{Abstract}

This paper introduces a new 2-country 4-region model in order to study the possible trade-offs arising between national efficiency and interregional equity, differentiating for different strengths of agglomeration economies and different regional productivities. In this static model the national policy maker can affect entrepreneurship through the set-up costs of firms.

It is evidenced that, for countries composed of identical regions, spatially dispersed allocations of public productive expenditure are more efficient with low agglomeration economies whereas spatially concentrated allocations are more efficient with high agglomeration economies. As the regions become different, however, unbalanced allocations of public productive expenditure towards the most advanced region become more efficient also in case of relatively weak agglomeration economies, until, for regions sufficiently different, the most efficient allocation of public productive expenditure is always to concentrate it in the most advanced territories.

For this reason, if some sort of lump-sum compensating mechanisms are available, short-sighted national policy makers, not taking into account long-run growth and factor mobility, can rationally decide to support the competitiveness of the already more-productive regions and transfer income to the lagging ones, a behaviour which is shown to have significant similarities with two real cases. 


\section{Introduction}

A large number of economic models have been developed in the past 15 years in order to explore endogenous regional growth and the location of economic activities, with the consequent differentials of development among territories. These developments appear, however, to have taken place without paying enough attention to the effects entailed by regional policies from an aggregate point of view. National policies designed to reduce regional inequalities may in fact turn-out to be sub-optimal from a country-wide perspective. Unfortunately, it is too often unclear under which values of parameters regional policies are also able to increase the aggregate economic performance of nations (or over-national communities) and which policies are, instead, to be simply considered as a means to increase the equality of income across space.

In the past, the issue of the compatibility of national economic efficiency with a flatter spatial pattern within the country used to be a very important one. The most diffused belief was that interregional equity and national efficiency would normally be achieved at the same time due to decreasing returns. The relative failure of many regional policy attempts, which weren't able to induce growth and convergence, and the introduction of increasing returns in economic models, have then shown the possibility of a trade-off.

For some time, this issue hadn't been at the core of the researchers' attention, but is returning to the theoretical limelight. The scarcity of available resources - due to tighter financial constraints - is making the analysis of the effects of regional policies on the overall efficiency of the economic system more important, since it has now become crucial to know wether truly new resources have become available (as in the traditional approach that used to see regional policies as pure development policies) or if there is a price in terms of efficiency, or aggregate income, to be paid in favour of an increased equity between regions. To say it with the words of the chairman of the Board of Directors of the EIB:

"In the past, the consensus was that regional policy could support growth, and that convergence would come about by poorer regions catching up with richer ones. Increased equality and growth could go hand in hand. Recent experience has led a number of commentators to question this. They argue that there are strong economic forces that lead to divergence between regions. Regional policy cannot do much to overcome these forces. This means that regional spending is simply a transfer of income from rich to the poor - with little effect on productivity gap in poor regions. Indeed, this may led to lower overall prosperity if it drains resources from those wealthy innovative regions that are the main engines of economic growth. If this is the case we face a trade off between equality and growth", (Maystadt, 2000, p.4).

This paper investigates when the trade-off arises within a static context, using a new model which is able to represent different levels of economies 
of agglomeration and multi-regional countries. The purpose of the analysis is to assess the effects of regional productivity differentials on the optimal choices of policy makers.

Most economic literature still regards regional policy in terms of infrastructural policy, or even more specifically, in terms of mere transport infrastructure, which used to constitute the bulk of many interventions until the early 90s. However, this type of intervention already had a large number of exceptions, for example the policies inspired by the Perroux's Growth Poles theory (Darwent, 1969). The focus on infrastructure is mainly due to the difficulty of modelling complex territorial aspects, especially the relational ones, but, in some cases, one could also conjecture a simplified understanding of regional policies. Most economists, however, are now aware of the large amount of work that remains to be done in that direction, for example Baldwin et al. (2003).

Different from most of the literature, regional policy is here modelled innovatively: the model represents in fact territorial policy affecting entrepreneurship, in particular allowing the nation state to act on the set-up costs of firms.

The paper is organized as follows: Section 2 introduces the desired properties of regional policies, with a simple taxonomy that allows to compare them; Section 3 surveys the recent relevant contributions - it has to be stated in advance that most of these contributions involve agglomeration, whereas, for the purposes of this paper, only agglomeration economies are needed and modelled; Section 4 introduces a two-country, four-region model able to analyse the issue, especially what happens to equity and efficiency if the regions are different from each other. Section 5 uses the model in order to investigate equity and efficiency according to the theoretical framework of Section 2 and mentions two empirical cases that bear strong similarities to the predictions of the model. Section 6 concludes the study.

\section{Desired properties of regional policies}

With the introduction of models with imperfect competition (Dixit and Stiglitz, 1977) and consequent agglomeration (Krugman, 1991a,b, Ottaviano and Puga, 1998, Fujita et al., 1999, Neary, 2001, Fujita and Thisse, 2002) questioned first was the linearity of the relationship between transport costs and regional development, then, partly as a consequence, the linearity of regional development, since increased attention has been devoted to issues such as history, the lock-in and expectations (Ottaviano, 1999, 2001, Baldwin, 2001). It is interesting to remember that, in models with multiple equilibria, a force that pulls the economy out of an unstable equilibrium cannot normally be counterbalanced by a successive and opposite force of

the same size; this is because of cumulative effects that move the system 


\begin{tabular}{|c|c|c|c|}
\hline \multirow{2}{*}{\multicolumn{2}{|c|}{$\begin{array}{l}\text { EQUILIBRIA } \\
\text { OF MODELS }\end{array}$}} & \multicolumn{2}{|c|}{ Regional Disparities } \\
\hline & & High & Low \\
\hline \multirow{2}{*}{ 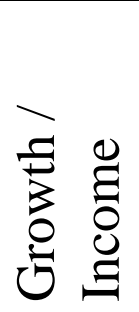 } & High & II & $\begin{array}{l}\text { I (Best } \\
\text { situation) }\end{array}$ \\
\hline & Low & $\begin{array}{l}\text { III (Worst } \\
\text { situation) }\end{array}$ & IV \\
\hline
\end{tabular}

Table 1: Classification model equilibria.

towards the stable equilibrium (or one of the stable equilibria when more than one exists).

We can represent the possible equilibria of multi-regional models of location/agglomeration in a four-quadrants graph (Table 1). We will have on the vertical axis growth or income (depending if the model is dynamic or static), measured for the whole country; the horizontal axis represents the extent of regional disparities. Both axes should actually be depicted on a continuous scale, but in the discreet form the meaning and implications are more evident.

When decreasing returns are present, like in exogenous growth models (Solow, 1956) or in traditional location models, the maximum income is achieved in a dispersed equilibrium, the same one that we indicated in quadrant $\mathbf{I}$ as "best situation", since it is optimal from a Paretian point of view.

When increasing returns are present, on the contrary, a number of models, especially of the New Economic Geography (NEG, the most relevant for our purposes of those will be mentioned in the next section) have outlined that the equilibrium is more likely to be one with high income/growth and high agglomeration at the same time, even if for some values of the parameters it is generally possible to have situations of high income/growth and low agglomeration, or (and this is the worst case) situations in which regional disparities are high despite of a low income/growth. For example, Ottaviano and Thisse (2002) have identified a case of market failure in which, for intermediate transport costs, the market outcome is agglomeration, even if a dispersed allocation would be desirable on both equity and efficiency grounds.

The theoretical developments of the last 15 years, therefore, have some- 


\begin{tabular}{|l|l|l|l|l|}
\hline \multicolumn{2}{|l|}{$\begin{array}{l}\text { EFFECTS OF } \\
\text { REGIONAL } \\
\text { POLICIES }\end{array}$} & \multicolumn{2}{l|}{ Regional Disparities } \\
\cline { 3 - 5 } & Increase & No effect & Decrease \\
\hline \multirow{2}{0}{} & Increase & $\begin{array}{l}\text { III (policies } \\
\text { targeting efficiency } \\
\text { at detriment of } \\
\text { equity) }\end{array}$ & $\begin{array}{l}\text { II (policies targeting } \\
\text { efficiency) }\end{array}$ & $\begin{array}{l}\text { I (policies targeting both } \\
\text { equity and efficiency) }\end{array}$ \\
\cline { 2 - 5 } & $\begin{array}{l}\text { No } \\
\text { effect }\end{array}$ & $\begin{array}{l}\text { IV (damaging } \\
\text { policies) }\end{array}$ & $\begin{array}{l}\text { Ineffective } \\
\text { Policies }\end{array}$ & $\begin{array}{l}\text { VIII (policies } \\
\text { targeting equity) }\end{array}$ \\
\cline { 2 - 5 } & Decrease & $\begin{array}{l}\text { V (damaging } \\
\text { policies) }\end{array}$ & $\begin{array}{l}\text { VI (damaging } \\
\text { policies) }\end{array}$ & $\begin{array}{l}\text { VII (policies targeting } \\
\text { equity at detriment of } \\
\text { efficiency) }\end{array}$ \\
\hline
\end{tabular}

Table 2: Classification of the possible effects of regional policies.

what reversed the pattern of the most reasonable theoretical relationships between growth and agglomeration, from one which saw quadrants $\mathbf{I}$ and III as the most likely to occur to a pattern in which the relationship is not linear, and it is also likely to find the economy in the quadrants II and IV. It must be noticed that the quadrants II and IV are not comparable from a Paretian point of view, and this poses another problem to the policy maker, who, even when having the instruments allowing her to chose one of the two stable equilibria, may be facing a trade-off between two desirable objectives.

The next step is therefore to build a 3 by 3 matrix in which to classify regional policies (Table 2) according to their effects on regional disparities and on the efficiency of the aggregate economic system, both considered, ceteris paribus, as desirable objectives.

Although nine situations are theoretically possible, only five of them are indeed logical choices for the policy maker. In fact, policies which have no effect are not worthwhile, especially if costly, and only a malevolent planner could choose to apply policies whose effects can be classified in quadrants IV, V and I. Unfortunately, even if not designed with that purpose, it is possible that, once implemented, some policies indeed have detrimental effects, but this has to be considered an unintentional effect and will not be discussed further.

The regional policies which can be reasonably implemented by a benevolent planner are those of quadrants I, II, III, VII and VIII. There may in fact be policies targeting the efficiency of the aggregate system, for example when congestion dis-economies are present, and policies targeting equity in 
space, either because this is considered a viable way to reduce the differences of income across the population, or because in this way it is possible to foster "cohesion" within a state or a supra-national body as the EU.

The two objectives may be disjointed (policies belonging to quadrants II and VIII) or can be targeted simultaneously by just one policy (quadrant I). The latter is the case of the EU Cohesion Policy, which tries to be a means to increase the cohesion of the Union by reducing regional disparities and allowing more balanced and also higher growth, as stated in the 3rd Cohesion Report:

"Strengthening regional competitiveness through well-targeted investment throughout the Union and providing economic opportunities which help people fulfil their capabilities will thus underpin the growth potential of the EU economy as a whole to the common benefit of all. By securing a more balanced spread of economic activity across the Union, regional policy helps to reduce the pressures of over-concentration, congestion and bottlenecks" (Commission, 2004, p. xxvi-xxvii).

Whether in the past the EU regional policy has been able to achieve these two objectives is still matter of an intense debate which goes far beyond the scope of this paper.

This classification is compatible with what is found in textbooks (Vanhove, 1999): if, for example, efficiency is the objective pursued by national/industrial policies and the decrease of regional disparities is the objectives of regional policies, policies falling in the quadrant $\mathbf{I}$ can be seen as "perfect compatibility". In quadrants II and VIII are policies of "neutral compatibility" and in of quadrants III and VII those of "incompatibility".

As is obvious, the policies of quadrant $\mathbf{I}$ are the most loved by politicians; unfortunately, not all policies, suggested or implemented, belong to this quadrant, but in some cases it may be found convenient to market such policies as "quadrant-I".

The presence of some sort of strong positive externalities is commonly considered in the literature the cause for the existence of a trade off between growth and spatial dispersion which would force regional policies to fall into quadrants III and VII; this is the case of the improvement of transport infrastructure between regions in the Core-Periphery (Fujita et al., 1999, Krugman, 1991a) model: the likely result is in fact increased agglomeration, which makes the inhabitants of the core region richer to the detriment of those of the other region.

Policies of types III and VII, despite of the fact that they are not comparable from a Paretian point of view, can in any case be implemented by a benevolent policy maker, but they need a political decision on which objective is more important and, consequently, also need a stronger political consensus.

If the policy aimed at the improvement of efficiency (Markusenn, 1996) targets some high-tech sectors, as it is currently often the case, there is larger 
scope for the incompatibility of the objectives, due to the fact that these sectors spontaneously tend to concentrate in the most advanced regions where external economies are higher. On the contrary, if some congestion diseconomies are present (Vanhove, 1999), the decrease of spatial concentration and the improvement of national efficiency can come together.

In the literature, often cited as a reason for the compatibility of objectives, is the inflationary consequences of agglomeration, so that countries with lower concentration of economic activities will tend to have a lower Phillips curve (Higgins, 1988). Today, since inflation is no longer perceived as a paramount problem, this aspect is often neglected. This neglect also appears because most models, in order to remain simple and analytically solvable, tend to leave out monetary issues.

Empirically, for example, Davies and Hallet (2002) find some evidence of a trade-off between national growth and regional dispersion in the cases of Spain and Ireland; on the contrary, in non-Cohesion countries, they find evidence of a spread effect for which the reduction of regional disparities has induced a positive effect on growth. The literature on trade, moreover, usually finds empirically that, with trade becoming freer, there is larger growth but divergence between countries.

Unfortunately, the political decision-makers are not always aware of the possible drawbacks of the policies they are going to implement. This problem is made even more evident by the fact that the same policy can have very different results if applied to different contexts, and too often the theory upon which these policies rest is too simplified to distinguish among these different contexts.

Indeed, one of the criticisms of Martin (1998b) regarding the New Economic Geography theories resides in the fact that space is overly simplified and lacks of realism, so that, with no insights about the specificity of territory, it is nearly impossible to produce policy prescriptions. Although there have been some advancements in this aspect, much more is still needed. Also most authors of the NEG agree, and are consequently trying to extend their models with the purpose of taking into account a deeper description of spatial aspects (Ottaviano and Thisse, 2003).

\section{Regional policy in growth, agglomeration and public finance models}

The spatial impossibility theorem (Starrett, 1978) affirms that when transport is costly and space is homogenous, then no equilibrium exists which involves the movement of goods. For this reason (Thisse, 2000) when agglomeration exists, it is due to one or more of the following items: heterogenous space; market externalities - either in production or in consumption; 
some kinds of non-competitive markets ${ }^{1}$. The market outcome will be optimal in the first case, but some interventions will be justified in the other two. In particular Thisse (2000), using the model of Ottaviano et al. (2002) shows that for high transport costs the equilibrium is a dispersed pattern and this pattern is efficient; the same happens for low transport costs, when the equilibrium and more efficient pattern involves agglomeration. On the contrary, when transport costs take intermediate values, there is more agglomeration than efficient and, hence, some room for regional policy which could increase both equity and efficiency.

The introduction of space, however, can also be used in order to achieve perfect competition in models with increasing returns, as recently shown by Berliant and ben Raa (2004). This is further proof that adding the spatial dimension to economic models leads to important complications and, even more importantly, to results that are highly dependent on the hypotheses.

Martin and Rogers (1995) have developed a model of location with public infrastructures which is capable of leading to two important conclusions. First, there is some circular causation between the provision of infrastructure and agglomeration; in fact, a country where there is more production generates more output - and consequently tax revenue - ensuring the momentum to advance that country's infrastructure more than that of a lagging country. This can be also applied to regions where there is some sort of fiscal federalism, or where the nation state allocates its resources by also taking into account the revenue that it gets from the various regions. The second conclusion arising from the Martin and Rogers model is that there is a big difference in results between infrastructures that facilitate domestic trade and those that facilitate the international one. The former leads to an increase in efficiency and production within the domestic area; the latter in most cases leads to larger aggregate economic production but also to greater agglomeration, to the detriment of the less advantaged country/region. As in generally all the New Economic Geography models, the space scale is not actually specified, and therefore the model can be used either between nations at the European level or between regions at a country level.

Philippe Martin (1998a, 1999b,a, 2000), following his work of 1995, is the author that has most explicitly addressed the issue of the relationship between equity and efficiency in regional policy. The first of these contributions Martin (1998a) questioned the linearity of the relationship between growth and localisation, and using the model of Martin and Ottaviano $(1996,1999)$, he evidenced the possibility that higher agglomeration and higher growth coincide (quadrant II of Table 1).

\footnotetext{
${ }^{1}$ Hurst et al. (2000) identify three main groups of possible market failures: the existence of substantial technological externalities; the presence of pecuniary externalities, which could lead to excessive agglomeration; the presence of a minimum threshold, so that either new businesses need a minimun scale or a lack of adequate information on market and production conditions may prevent new activities from implanting in a new area.
} 
In the second article Martin (1999b), using a model with both growth and agglomeration, achieved the conclusion that there exists a trade-off between growth and an even spatial distribution of economic activities. He showed that the effects of an increment of infrastructure that ease the commerce of goods within a poor region are: a lower concentration of industries, a lower growth rate and, un-intuitively, an increase in the income gap between the regions. On the contrary, he showed that infrastructure that decreases transport costs between regions increases agglomeration, increases growth and decreases nominal income disparities, but with an ambiguous effect on real disparities since the impact on the price index of the regions is complex. The policies that increase the rate of innovation, finally, have a win-win effect, since they both increase the growth rate and reduce regional disparities, belonging therefore to quadrant $\mathbf{I}$ of Table 2 .

In the third article Martin (1999a), using the theoretical conclusions of the previous paper, shows that, in the light of the trade off between growth and spatial equality, the EU will need to re-define its policy objectives, in particular that market failures have both to be identified and to become the fundamental target of policies. The paper also supports policies that try to make communication and the transfer of innovation across space easier; the author also supports policies that increase the mobility of workers in order to decrease regional income disparities. This conclusion is shared by Puga (2002) and Hurst et al. (2000), even if other authors have evidenced that the effects of workers' mobility are not necessarily straightforward (Leach, 1996).

The conclusions about regional policy achieved in the New Economic Geography literature have been efficiently synthesized in the book "Economic Geography and Public Policy" by Baldwin et al. (2003), mainly using an extended version of the "localised spillovers" model developed by Martin (1998a, 1999b). The book models as intra-regional and inter-regional trade costs many features including, among others, infrastructure; in this way the authors are able to discuss the effects of a number of regional policies.

The first policy experiment is a continuous transfer of income from the north to the south ${ }^{2}$ which lowers income inequality and spatial concentration, but also lowers the growth rate of the whole country (quadrant VII of Table 2). As already evidenced by the original article (Martin, 1999b), an infrastructure that facilitates intra-regional trade in the south lowers agglomeration, lowers aggregate growth and increases nominal income inequality both between regions and between workers and capital owners. Infrastructure that decreases inter-regional transport costs increases growth and spatial concentration, and decreases nominal income inequalities again both between

\footnotetext{
${ }^{2}$ Also in this case, as in nearly all two-regional models, the North is used to indicate the advanced (agglomeration) region and the South the lagging one, as it is used in the literature about asymmetric models of trade and growth (Chui et al., 2002).
} 
regions and between workers and capital owners. Policies that facilitate technology spillovers across regional boundaries increase growth in the whole economy, decrease spatial concentration and decrease nominal inequalities between regions, and between workers and capital owners (quadrant $\mathbf{I}$ of Table 2).

In the context of a three-regional country they also obtain the interesting result that, if the central region is the poorest, decreasing transport costs lead to a re-location of economic activities towards the central region provided that its share of expenditure is sufficiently high.

Baldwin et al. (2003) then introduce congestion costs and show how, in this case, lower transport costs between regions may put the economy in an equilibrium with low growth, high spatial concentration and high regional income inequality, the worst case of Table 1 (quadrant III).

Finally, their analysis is extended to show how infrastructure improvements have non-linear effects: in particular, an improvement of infrastructure within the poorer region may have no effect at all until a certain threshold is reached and, then, convergence suddenly occurs between the two regions.

Lanaspa and Sanz (2004) further extend the model of Martin and Rogers (1995) in order to consider that infrastructure can have differential effects on imports and exports. They chose to classify a large number of infrastructure (and, hence, of policy interventions) into four types, depending on wether they are domestic or international and if they affect import or export costs. The results they get with the model show that the most effective policy for a region interested in attracting more industry is to improve its domestic and international export infrastructure, whilst the investment in transport or international import infrastructure does not have a clear effect. Concerning the welfare of regions, attracting industries always increases regional welfare, even if it proves to be to the detriment of the other region. Their analysis, in fact, does not focus on general welfare implications.

In a previous contributions, the same authors (Lanaspa et al., 2001) extended the core-periphery model (Krugman, 1991b) to include the public sector, with the result that regions with a lower tax burden or with a more efficient public sector are generally more attractive to firms' location. The other effect they observe is that the influence of transport costs becomes dependent on the size of the public sector, so that the relationship between these costs and agglomeration is no longer monotonous as it was in the original C-P model.

An valuable development regards the analysis of regional policy in models which explicitly introduce non-traded goods in the economy. Behrens (2004), using and extension of the model by Ottaviano et al. (2002) shows that more complex spatial structures can emerge, in particular that partial agglomeration is possible. Other interesting aspects to investigate are the scope and effects of regional policy in models which introduce taste heterogeneities in the line of probabilistic migration theories, like the one 
of Murata (2003), or in models that introduce asymmetries in the regions, such as Lanaspa and Sanz (1999) who use different agricultural populations in the C-P model as a proxy of heterogeneous quality of land, or in models in which congestion is possible (Lanaspa and Sanz, 2001).

Ottaviano (2003) lists the general policy implications of New Economic Geography models: first all policies (tax, competition, trade, etc.) usually have spatial effects, and these effects should be taken into account. Second, the impact of regional policies is highly dependent on the extent of trade integration, in general the effect is more important when barriers are lower and goods and capital are more footloose. Third, threshold effects exist, since policies can have no effect until a threshold is reached and, then, the effect is catastrophic. On the other hand, due to the existence of lock-in, temporary policies can have permanent effects due to locational hysteresis and self-reinforcing mechanisms. Finally, policies can be very effective when they act as a selection mechanism able to lead the economic system towards the desirable equilibrium, if the starting point is not a stable equilibrium.

An important theme in regional integration and policy, which is increasingly integrated into agglomeration models, is fiscal competition (see the work of Wildasin (2003) for a recent and encompassing model): regions can compete by decreasing taxes in order to attract firms and, in this way, increase their welfare at the other region's expenses; unfortunately this may lead to a "race to the bottom", and regional authorities end up by decreasing taxes or giving subsidies to firms at a level which is no longer justifiable in economic terms: this is known as Tiebout mechanism. One way of coming out of this has been identified. If firms are different enough (Justman et al., 2001) in the regional differentiation of the quality of infrastructure, each region would provide and be paid for a certain quality of infrastructure, which a group of firms would then chose as its better compromise and which would consequently lead to a choice of location. Another factor lowering fiscal competition (Bjorvatan and Schjelderup, 2002) is the presence of international spillovers of locally provided public goods, which are unfortunately not able to induce the first best outcome because of the problem of free riding among regions. Moreover, they show that congestion can lead to an under-provision of public goods.

Finally, Ludema and Wooton (2000) show that, contrary to the most commonly held belief, regional integration can decrease the intensity of tax competition, restoring rather than eroding fiscal autonomy; this happens, in economic geography models, especially when agglomeration forces are high.

In a recent paper, Dupont and Martin (2003) study the effects of a number of subsidies to mobile firms as a form of regional policy, and come to an unpleasant conclusion: since it is the core who owns more capital, such subsidies, even if financed at the national level and introduced in the poorer regions, may increase inequality and will ultimately fall in quadrants III, IV or $\mathbf{V}$ of Table 2. 
In conclusion, it can observed that the problem of equity and efficiency, apart from a few articles, is no longer at the center of the theoretical investigation, despite the fact that the explicit introduction of agglomeration into models has given rise to a number of models that are able to call into question the simpler older, albeit simpler, conclusions.

Above all, very little attention has been paid to what happens when regions are different from one another. For this reason, the following section introduces a simple model in which the regions of a country are allowed to be structurally different. This model involves economies of agglomeration, even if dynamic agglomeration (i.e. the one depending on the re-location of economic agents) is not modelled to keep the model parsimonious and solvable.

\section{Regional policy in a two countries four regions model}

In Section 2, a framework has been developed to classify the effects of regional policies on the two axes of equity and efficiency (Table 2). These effects may depend on a number of factors, including the strength of agglomeration economies, the dynamic or static framework and the characteristics of the regions of which a country is composed. In particular, the previous section has shown that the presence of different regions is a factor where there has been little investigation.

Following these arguments, in order to analyze the relationship between regional characteristics, strength of agglomeration economies, and equity and efficiency effects of regional policies, this section introduces a model where these elements are combined in a simple, although not analytically solvable, manner.

This model does not use agglomeration and assumes that some structural differences among regions may exogenously exist; in this sense, if the possibility of structural rearrangement is implied in the long-run, this is a short-run model. The question that it is designed to answer is in fact: is there any trade-off between the aims of interregional equity and of economic efficiency, in particular when a country is composed of different regions?

In order to address the question, an economy consisting of two countries and four regions (two regions per country) is modelled. The model adopts the Dixit and Stiglitz (1977) monopolistic competition framework in which each firm produces one variety of goods. Goods are freely traded across regions and countries.

For simplicity, it is also assumed that only one factor of production exists, namely labour, and that, since this is a short-run model, labour is immobile across regions.

We also explicitly assume that agglomeration economies are present in 
the production of goods, so that each firm's production is positively affected by the presence of other firms in the same region. These positive externalities are the direct effect of agglomeration economies and will be counterbalanced by rising wages in regions with more firms, in addition to some degree of rivalry in the use of a publicly provided production factor.

Agglomeration economies, at their simplest, allow firms to be more productive in a region in which more firms are present. This may be modelled on the supply side, for example by making more productive the firms of regions where more firms are present, but for our purposes, it is equivalent and easier to model agglomeration economies on the demand side. We will therefore assume that the cost function of the firm is not affected by the presence of other firms in the same region, but rather it is the quality of the product which depends on the number of firms present in the region.

For this reason agglomeration economies are modelled with a modified CES utility function where the quantity of each good consumed coming from region $i\left(x_{i}\right)$ is replaced by $N_{i}^{\gamma} x_{i}$, where $N_{i}$ is the number of firms in region $i$ and $\gamma$ is the extent of agglomeration economies, $<1$ in order to assume that the increase of productivity is less than proportional to the number of firms present in the region; this mechanism is similar to the quality ladders used in the growth literature (Grossman and Helpman, 1991).

In absence of transport costs, the utility function of any consumer living in any of the four regions is therefore:

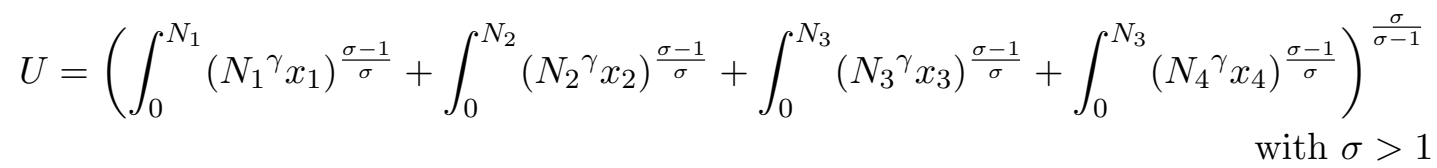

In order to analyze the effects of regional policy in terms of equity and efficiency, we introduce the possibility for the national government to freely allocate among its two regions $(i=1,2)$ a publicly provided production factor $P U B_{i}$.

The publicly provided production factor is assumed to decrease the requirement of investment of the firms of the region, i.e. their total set-up costs, in the same measure for all firms: $P U B_{i}$ is therefore non excludable within each region. We do not assume, however, that $P U B_{i}$ is a public good, since some degree of rivalry $(\delta)$ in the use of it is explicitly introduced. The public production factor works similarly to public business assistance services, which provide all the firms of the region with services that decrease their total set-up costs, but the higher the number of firms that use these services, the lower the assistance the public officials can give to each firm. The regional policy represented in this model therefore affects entrepreneurship. In particular, for different values of rivalry in the use of $P U B_{i}$, different types of policies can be represented. 
Because the standard monopolistic competition framework is symmetric, all firms within a region will take identical advantage of the publicly provided production factor, so that the cost function of any firm operating in region $i$ will be the following:

$$
C\left(x_{i}\right)=\left(F_{i}-\frac{P U B_{i}}{N_{i}^{\delta}}\right) w_{i}+a_{i} w_{i} x_{i}
$$

where $\delta$ is the parameter which represents the degree of rivalry in the use of the public production factor: it ranges from 0 to 1 , and the closer it is to 0 the more $P U B_{i}$ is closer to a public good (i.e. non-rival and non-excludable) within region $i$. When $\delta=1$, rivalry is total and the part of $P U B_{i}$ used by a firm can not be used by any other firm; in this limit case $P U B_{i}$ is more like a fixed subsidy to firms and $P U B_{i} / N_{i}$ is just the quota of this subsidy going to each firm. The quantity $F_{i}$ therefore represents therefore the fixed set-up cost of the firms, and the quantity $\left(F_{i}-\frac{P U B_{i}}{N_{i}^{\delta}}\right)$ their total set-up cost.

By solving the utility maximization it is possible to derive the price conditions for the demand equilibrium, which are, if we use the price of the good of region 4 as numeraire:

$$
\left\{\begin{array}{l}
p_{4}=1 \\
p_{1}=\left(\frac{N_{1}}{N_{4}}\right)^{\gamma \frac{\sigma-1}{\sigma}}\left(\frac{x_{1}}{x_{4}}\right)^{-\frac{1}{\sigma}} \\
p_{2}=\left(\frac{N_{2}}{N_{4}}\right)^{\gamma \frac{\sigma-1}{\sigma}}\left(\frac{x_{2}}{x_{4}}\right)^{-\frac{1}{\sigma}} \\
p_{3}=\left(\frac{N_{3}}{N_{4}}\right)^{\gamma \frac{\sigma-1}{\sigma}}\left(\frac{x_{3}}{x_{4}}\right)^{-\frac{1}{\sigma}}
\end{array}\right.
$$

Equation 3 can also be rearranged to obtain the demand of goods of one region with respect to those of another region once given the prices:

$$
\frac{x_{i}}{x_{j}}=\left(\frac{N_{i}}{N_{j}}\right)^{\gamma(\sigma-1)}\left(\frac{P_{j}}{P_{i}}\right)^{\sigma}
$$

Notice that the prices are affected by the quality of goods, represented by the number of varieties produced in each region.

\subsection{Simplified model}

Let's now study the supply side and firm behavior, starting with the limit case $\delta=1$ (complete rivalry) because it offers the possibility to obtain analytical solutions. Remembering that the behavior of all firms in each region is symmetric, the cost equation is now given by:

$$
C\left(x_{i}\right)=\left(F_{i}-\frac{P U B_{i}}{N_{i}}\right) w_{i}+a_{i} w_{i} x_{i}
$$


Each firm maximizes its profit by setting its price, once the demand function is known (Eq. 4). It can be shown that the market behavior of firms is not affected by the extent of agglomeration economies and is such that each firm's price is a mark-up on flexible costs depending on the demand elasticity, as in the usual Dixit and Stiglitz (1977) framework:

$$
p_{i}=\frac{\sigma}{\sigma-1} a_{i} w_{i}
$$

Since there is free entry of firms, the dimension of the representative firm is determined once determined which quantity produced and sold by the firms is sufficient to cover the fixed costs, i.e. when:

$$
\left(p_{i}-a_{i} w_{i}\right) x_{i}=\left(F_{i}-\frac{P U B_{i}}{N_{i}}\right) w_{i}
$$

The dimension of a firm is therefore dependent on the quantity of public endowment and on the number of firms in the region:

$$
x_{i}=\left(F_{i}-\frac{P U B_{i}}{N_{i}}\right) \frac{\sigma-1}{a_{i}}
$$

Since there is no mobility of labour, the number of firms is finally determined by the quantity of labour demanded by each representative firm $\left(L_{D i}\right)$ and the quantity of available labour $\left(L_{i}\right)$ :

$$
\begin{aligned}
N_{i}=\frac{L_{i}}{L_{D i}} & =\frac{L_{i}}{\sigma F_{i}-\sigma \frac{P U B_{i}}{N_{i}}} \\
\text { from which: } N_{i} & =\frac{L_{i}+\sigma P U B_{i}}{\sigma F_{i}}
\end{aligned}
$$

Consequently:

$$
X_{i}=\frac{F_{i}}{a_{i}}(\sigma-1) \frac{L_{i}}{L_{i}+\sigma P U B_{i}}
$$

Using equations 4, 7, 8 and 9 it is possible to obtain endogenously the ratio between the wages of one region and those of another, depending on the exogenous structural parameters of the regions:

$$
\frac{w_{i}}{w_{j}}=\left(\frac{L_{i}}{L_{j}}\right)^{-\frac{1}{\sigma}}\left(\frac{a_{i}}{a_{j}}\right)^{\frac{1-\sigma}{\sigma}}\left(\frac{F_{i}}{F_{j}}\right)^{\frac{-\gamma(\sigma-1)-1}{\sigma}}\left(\frac{L_{i}+\sigma P U B_{i}}{L_{j}+\sigma P U B_{j}}\right)^{\frac{\gamma(\sigma-1)+1}{\sigma}}
$$

This equation shows that the wage paid to the residents of a region increases with the amount of public factor allocated to that region, and decreases with the fixed and flexible cost requirements $\left(F_{i}\right.$ and $\left.a_{i}\right)$, i.e. the 
wage increases with the economic strength of the region, which is assumed to be an exogenous characteristic upon which the government has no possibility to intervene. Regional policy, in this model, doesn't have structural effects.

The effects of the size of the region $\left(L_{i}\right)$ is not straightforward. In fact, there exists a mass effect, due to the assumed agglomeration economies, and a congestion effect, due to the rivalry in the use of the publicly provided factor. We can study which effects prevails by computing the first order derivative:

$$
\begin{gathered}
\frac{\partial \frac{w_{i}}{w_{j}}}{\partial L_{i}}=L_{j}^{\frac{1}{\sigma}}\left(\frac{a_{i}}{a_{j}}\right)^{\frac{1-\sigma}{\sigma}}\left(\frac{F_{i}}{F_{j}}\right)^{\frac{-\gamma(\sigma-1)-1}{\sigma}}\left(\frac{1}{L_{j}+\sigma P U B_{j}}\right)^{\frac{\gamma(\sigma-1)+1}{\sigma}} \\
\left\{\frac{L_{i}^{-\frac{1}{\sigma}}}{\sigma}\left(L_{i}+\sigma P U B_{i}\right)^{\frac{\gamma(\sigma-1)+1}{\sigma}}\left[-L_{i}^{-1}+(\gamma(\sigma-1)+1)\left(L_{i}+\sigma P U B_{i}\right)^{-1}\right]\right\}
\end{gathered}
$$

The sign of the whole expression depends on the sign of $\left[-L_{i}^{-1}+(\gamma(\sigma-1)+1)\left(L_{i}+\sigma P U B_{i}\right)^{-1}\right]$, therefore the effect of size on wages is positive if $L_{i}>\frac{\sigma}{\gamma(\sigma-1)} P U B_{i}$ and negative otherwise.

It is now therefore clear that the congestion effect only prevails for very high endowments of $P U B$.

Now we can study the effects of different regional allocations of publicly provided production factor on the national aggregate GDP.

Since labour is the only factor and all revenues of firms are paid in wages until 0 profits are reached, then:

$$
G D P_{i}=L_{i} w_{i}
$$

For a simpler notation, let us define a $\beta$ which is the quota of public production factor allocated by the nation state to the first of the two regions belonging to the same country $(i$ and $j$ ):

$$
P U B_{i}=\beta P U B \quad P U B_{j}=(1-\beta) P U B
$$

The income of both domestic regions, calculated in terms of the numeraire (and foreign) region also depend on the structural parameters of the latter. If we indicate with $A$ this constant part of the expression, the incomes of regions $i$ and $j$ are:

$$
\begin{gathered}
G D P_{i}=A L_{i}^{\frac{\sigma-1}{\sigma}} a_{i}^{\frac{1-\sigma}{\sigma}} F_{i}^{\frac{-\gamma(\sigma-1)-1}{\sigma}}\left(L_{i}+\sigma \beta P U B\right)^{\frac{\gamma(\sigma-1)+1}{\sigma}} \\
G D P_{j}=A L_{j}^{\frac{\sigma-1}{\sigma}} a_{j}^{\frac{1-\sigma}{\sigma}} F_{j}^{\frac{-\gamma(\sigma-1)-1}{\sigma}}\left(L_{j}+\sigma(1-\beta) P U B\right)^{\frac{\gamma(\sigma-1)+1}{\sigma}}
\end{gathered}
$$


The national income is simply the sum of the two previous equations:

$$
G D P=G D P_{i}+G D P_{j}
$$

Let us study the effects of a movement of public endowment between one region and the other by computing the derivative of income with respect to $\beta$ and defining it with $R$ :

$$
\begin{aligned}
\frac{\partial G D P}{\partial \beta}=A P U B & (\gamma(\sigma-1)+1) L_{i}^{\frac{\sigma-1}{\sigma}} a_{i}^{\frac{1-\sigma}{\sigma}} F_{i}^{\frac{-\gamma(\sigma-1)-1}{\sigma}}\left(\left(L_{i}+\sigma \beta P U B\right)^{\frac{\gamma(\sigma-1)+1-\sigma}{\sigma}}+\right. \\
& \left.-\frac{L_{j}}{L_{i}}{ }^{\frac{\sigma-1}{\sigma}} \frac{a_{j}}{a_{i}}{ }^{\frac{1-\sigma}{\sigma}} \frac{F_{j}}{F_{i}}{ }^{\frac{-\gamma(\sigma-1)-1}{\sigma}}\left(L_{j}+\sigma(1-\beta) P U B\right)^{\frac{\gamma(\sigma-1)+1-\sigma}{\sigma}}\right) \equiv R(17)
\end{aligned}
$$

The effects of a modification of the allocation of public endowment depends therefore on all regional production and size parameters $\left(L_{i}, L_{j}, a_{i}, a_{j}, F_{i}, F_{j}\right)$, on also on the starting $\beta$ and on the amount of public endowment available $(P U B)$.

Equation 17 can also be used to find the optimum allocation, in terms of national efficiency, of public endowment between the 2 domestic regions $\left(\beta^{*}\right)$ :

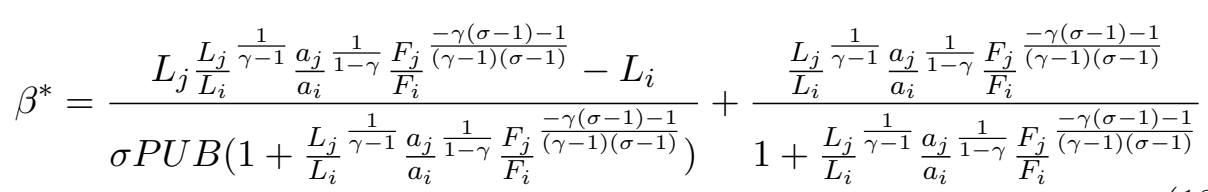

Next, it is possible to compute the derivatives of $\beta^{*}$ with respect to the parameters of the model, and define $S T R \equiv \frac{L_{j}}{L_{i}} \frac{1}{\gamma-1} \frac{a_{j}}{a_{i}} \frac{1}{1-\gamma} \frac{F_{j}}{F_{i}} \frac{-\gamma(\sigma-1)-1}{(\gamma-1)(\sigma-1)}$ in order to improve the readability of the results. $S T R$ can be interpreted as a value that defines the structural advantage of region $i$ with respect to region $j$ since it increases with $L_{i}, a_{j}, F_{j}$ and decreases with $L_{j}, a_{i}, F_{i}$.

$$
\begin{array}{r}
\frac{\partial \beta^{*}}{\partial L_{i}}=\frac{L_{i}-L_{j} S T R-\gamma L_{i}}{\sigma P U B(1+S T R)(\gamma-1) L_{i}}+\frac{\left(L_{j} S T R-L_{i}\right) S T R}{\sigma P U B(1+S T R)^{2}(\gamma-1) L_{i}}+ \\
-\frac{S T R}{(\gamma-1) L_{i}(1+S T R)}+\frac{S T R^{2}}{(1+S T R)^{2}(\gamma-1) L_{i}} \\
\frac{\partial \beta^{*}}{\partial L_{j}}=\frac{\gamma S T R}{\sigma P U B(1+S T R)(\gamma-1)}-\frac{\left(L_{j} S T R-L_{i}\right) S T R}{\sigma P U B(1+S T R)^{2}(\gamma-1) L_{j}}+ \\
+\frac{S T R}{(\gamma-1) L_{j}(1+S T R)}-\frac{S T R^{2}}{(1+S T R)^{2}(\gamma-1) L_{j}}
\end{array}
$$




$$
\begin{gathered}
\frac{\partial \beta^{*}}{\partial P U B}=\frac{L_{i}-L_{j} S T R}{\sigma P U B^{2}(1+S T R)} \\
\frac{\partial \beta^{*}}{\partial a_{i}}=-\frac{L_{j} S T R}{(1-\gamma) a_{i} \sigma P U B(1+S T R)}+\frac{\left(L_{j} S T R-L_{i}\right) S T R}{\sigma P U B(1+S T R)^{2}(1-\gamma) a_{i}}+ \\
-\frac{S T R}{(1-\gamma) a_{i}(1+S T R)}+\frac{S T R^{2}}{(1+S T R)^{2}(1-\gamma) a_{i}} \\
\begin{array}{c}
\frac{\partial \beta^{*}}{\partial a_{j}}=\frac{(22)}{(1-\gamma) a_{j} \sigma P U B(1+S T R)}-\frac{\left(L_{j} S T R-L_{i}\right) S T R}{\sigma P U B(1+S T R)^{2}(1-\gamma) a_{j}}+ \\
\frac{\partial \beta^{*}}{\partial F_{i}}=-\frac{S T R a_{j}^{2}(1+S T R)}{(\gamma-1)(\sigma-1) F_{i} \sigma P U B(1+S T R)}+\frac{\left(L_{j} S T R-L_{i}\right) S T R(-\gamma(\sigma-1)-1)}{\sigma P U B(1+S T R)^{2}(\gamma-1)(\sigma-1) F_{i}}
\end{array} \\
-\frac{S T R(-\gamma(\sigma-1)-1)}{(\gamma-1)(\sigma-1) F_{i}(1+S T R)}+\frac{S T R^{2}(-\gamma(\sigma-1)-1)}{(1+S T R)^{2}(\gamma-1)(\sigma-1) F_{i}} \\
\frac{\partial \beta^{*}}{\partial F_{j}}=\frac{(23)}{(\gamma-1)(\sigma-1) F_{j} \sigma P U B(1+S T R)}-\frac{\left(L_{j} S T R-L_{i}\right) S T R(-\gamma(\sigma-1)-1)}{\sigma P U B(1+S T R)^{2}(\gamma-1)(\sigma-1) F_{j}}+ \\
+\frac{S T R(-\gamma(\sigma-1)-1)}{(\gamma-1)(\sigma-1) F_{j}(1+S T R)}-\frac{S T R^{2}(-\gamma(\sigma-1)-1)}{(1+S T R)^{2}(\gamma-1)(\sigma-1) F_{j}}
\end{gathered}
$$

The analysis of the derivatives in this simplified model shows therefore that the behavior of the model is complex and depends, in addition to the market and demand parameters, on the parameters of the regions, i.e. on their specific structure.

The next section will analyze the model without the simplifying assumption on $\delta$ in order to obtain more general results with which to confront the starting theoretical framework.

\subsection{General model}

This section works out the more general case in which there is some degree of rivalry in $P U B_{i}(\delta<1)$. The demand side of the model is unaffected, the supply side, instead, changes as implied by Equation. 2 instead of Equation. 5 .

The profit maximization leads again to a firm price set-up equation which is a fixed mark up on variable costs, depending on the elasticity of demand, exactly as in Equation. 6. 
The dimension of firms, however, changes and becomes:

$$
x_{i}=\left(F_{i}-\frac{P U B_{i}}{N_{i}^{\delta}}\right) \frac{\sigma-1}{a_{i}}
$$

The labour demand of each firm, together with the fixed labour endowment of the region $\left(L_{i}\right)$, gives the number of firms present in each region. Since:

$$
N_{i}=\frac{L_{i}}{L_{D i}}=\frac{L_{i}}{\sigma F_{i}-\sigma \frac{P U B_{i}}{N_{i} \delta}}
$$

the number of firms is determined by the solution to the following equation:

$$
\sigma F_{i} N_{i}-\sigma P U B_{i} N_{i}^{1-\delta}-L_{i}=0
$$

This equation does not have an analytical solution for any $\delta$ but the solution can be numerically computed case by case and indicated with a placeholder:

$$
\hat{N}_{i}=\operatorname{RootOf}\left(\sigma F_{i} N_{i}-\sigma P U B_{i} N_{i}^{1-\delta}-L_{i}=0\right)
$$

The demand side of the model is still represented by equations 3 and 4 , in which we can now substitute the values obtained by the supply side in order to get the wage ratio between two regions:

$$
\frac{w_{i}}{w_{j}}=\left(\frac{\hat{N}_{i}}{\hat{N}_{j}}\right)^{\frac{-\gamma(\sigma-1)-1}{\sigma}}\left(\frac{L_{i}-\frac{P U B_{i}}{\hat{N}_{i}^{\delta}}}{L_{j}-\frac{P U B_{j}}{\hat{N}_{j}^{\delta}}}\right)^{-\frac{1}{\sigma}}\left(\frac{a_{i}}{a_{j}}\right)^{\frac{1-\sigma}{\sigma}}
$$

Since the GDP of the two region country is still $L_{i} w_{i}+L_{j} w_{j}$, once represented with $A$ all that which belongs to the foreign numeraire region, the GDP of the country becomes:

$G D P=A\left[L_{i} \hat{N}_{i}^{\frac{\gamma(\sigma-1)}{\sigma}}\left(L_{i}-\frac{\beta P U B}{\hat{N}_{i}^{\delta}}\right)^{-\frac{1}{\sigma}} a_{i}^{\frac{1-\sigma}{\sigma}}+L_{j} \hat{N}_{j}^{\frac{\gamma(\sigma-1)}{\sigma}}\left(L_{j}-\frac{(1-\beta) P U B}{\hat{N}_{j}^{\delta}}\right)^{-\frac{1}{\sigma}} a_{j}^{\frac{1-\sigma}{\sigma}}\right]$

The relationship between country GDP, regional GDPs and $\beta$ can now be studied numerically, for any value of the parameters. Obviously this general framework encompasses the limit case of Section 4.1. From now on, the 
analysis will concentrate on a national (supra-regional) perspective. For this reason, what happens in the foreign country will be left out of the analysis, in particular with the assumption that, when the two domestic regions are identical, the two foreign regions are also identical to the domestic ones, and, when the domestic ones are different, the two foreign regions are both equal to the average of the domestic regions.

\section{$5 \quad$ Equity, efficiency and regional policy}

The relationship between economic efficiency and regional policy (vertical axis of Table 2) can be analyzed in the model by studying aggregate GDP as a function of $\beta$.

In the simplified case, although the most efficient $\beta$ (hereafter $\beta^{*}$ ) could be any value between 0 and 1 depending on the structural differences of the regions, the curvature of the graph were always concave. This was because the rivalry in the use of $P U B$ was extreme, so that, with identical regions, a dispersed regional policy was always the best choice (Figure 3 on top).

In the general case in which the degree of rivalry is not extreme, the curvature of the graph depends on the strength of the agglomeration economies. In particular, if these are strong enough $\left(\gamma>\gamma^{\diamond}\right.$, with $\gamma^{\diamond}$ depending on $\delta$ and $\sigma$ ) the previous result is reversed, and the most efficient policy choice with identical regions is to give to one of the two all the publicly provided production good (Figure 2 on top). As in the previous case, however, the optimal $\beta^{*}$ can be any value between 0 and 1 when the regions are different, depending on regional structures and sizes.

The curvature of the function is in fact due to two concurrent effects: the strength of agglomeration economies, represented by $\gamma$, and the degree of rivalry in the use of the public production factor, measured by $\delta$, and this for each value of love for variety $\sigma$.

When agglomeration economies are strong with respect to congestion, and regions are identical, then the most efficient policy for the government is to encourage the set-up of the maximum number of firms in just one region by decreasing the total set-up cost there, even to the detriment of the other region's costs. When regions are identical but agglomeration economies are low, on the contrary, the most efficient policy is to implement a balanced policy between the regions, even when, as in this case, the only target is aggregate GDP.

The case with identical regions is not surprising, and we can also represent the space of the other parameters in which the relationship is concave: given any value of love for variety $(\sigma)$ and any value of rivalry in the use of the public production factor $(\delta)$, it is possible to know how large agglomeration economies have to be in order to have a concave relationship between $\beta$ and aggregate GDP. 

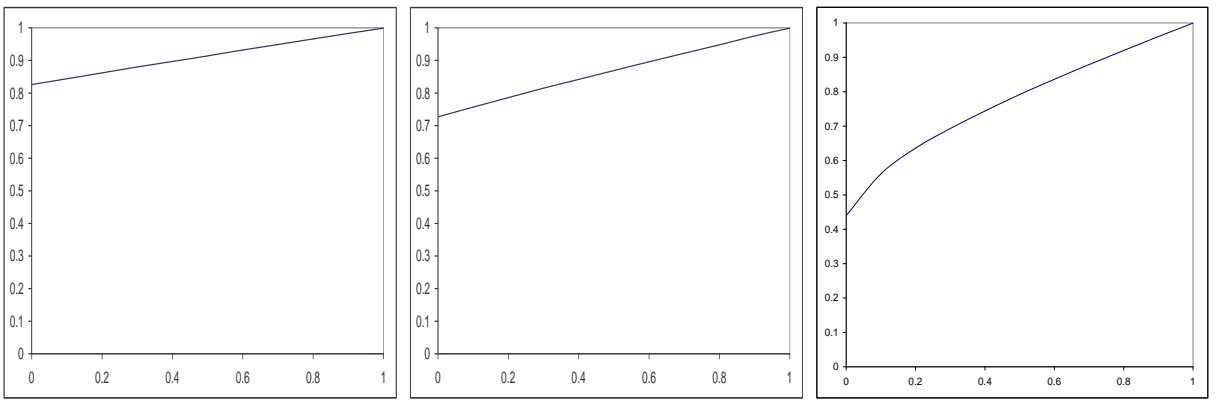

Figure 1: Relationship between $\gamma$ and $\delta$ : in the upper part of the squares the relationship between $\beta$ and total GDP is concave. ( $\gamma$ on the horizontal axis; graphics for $\sigma=1.5 ; 2.0 ; 4.0)$.

Figure 1 plots this for different values of $\sigma$ : in this figure, the area above the line is the one in which agglomeration economies are low and rivalry effects prevail so that the relationship is concave. This area decreases in size when love for variety $(\delta)$ increases $^{3}$, the opposite happens in the area below the line.

From now on, a case in which, for identical regions, the relationship between $\beta$ and national GDP is convex (all points belonging to the area below the line) will be defined as a case of "strong agglomeration economies"; the opposite case will be referred to as "weak agglomeration economies".

When the two regions are different, the results are more complex. For example, the fact that one region is more productive than the other (i.e. $a_{i}$ is smaller), normally gives this region an advantage due to the agglomeration economies assumed in the model: graphically, this is depicted by a shift of the $\beta^{*}$ (the $\beta$ that maximizes GDP, as seen at page 4.1) towards this region. When agglomeration economies are high, (Figure 2) $\beta^{*}$ becomes 0 or 1 depending on which region is stronger. When agglomeration economies are low (Figure 3), as far as regional productivities become increasingly different, $\beta^{*}$ moves from 0.5 towards an unbalanced value, until we reach a situation in which the maximum efficiency is to give all public support to the larger region.

A qualitatively similar pattern happens when the two regions are different in their other structural characteristics, for instance the fixed set-up costs of firms $\left(F_{i}\right)$ or their size $\left(L_{i}\right)$; we remember that wages are endogenous in the model.

\footnotetext{
${ }^{3}$ Notice that, although the relationship between $\beta$ and GDP may have some flexes, they don't normally fall in the relevant interval $(\beta=[0,1])$ apart from cases of for very low values of $\gamma$ where there is a very tiny and almost negligible interval around the point in which the function shifts from concave to convex.
} 

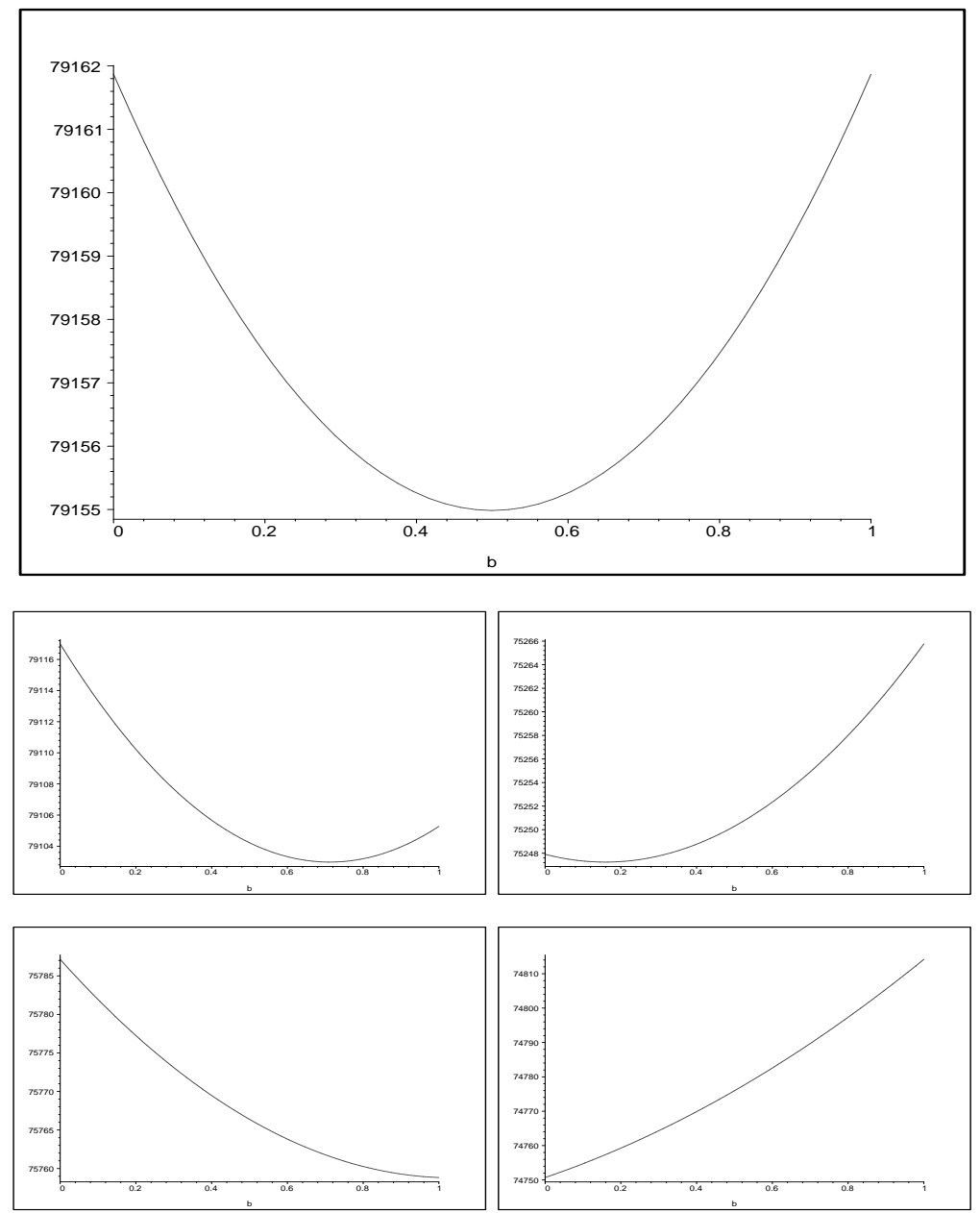

Figure 2: The relationship between $\beta$ and national GDP in case of strong agglomeration economies: results with identical regions (top) with slightly different regions (middle) and with more different regions (bottom). 

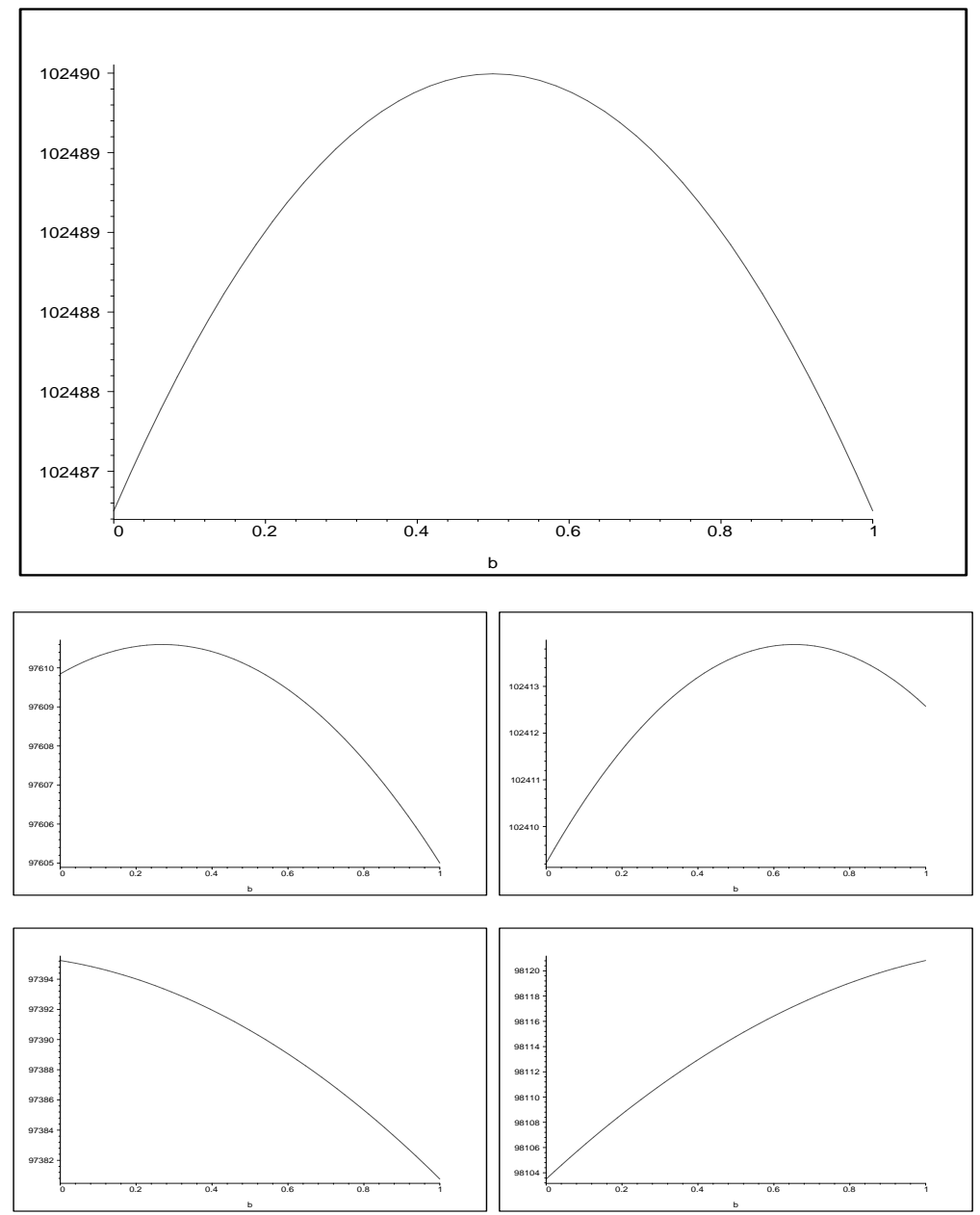

Figure 3: The relationship between $\beta$ and national GDP in the extreme case of complete rivalry or in case of weak agglomeration economies: results with identical regions (top) with slightly different regions (middle) and with more different regions (bottom). 
In order to interpret the results of the model, we still need to analyze the equity issue (horizontal axis of Table 2). This is much easier than the previous analysis, since, in the trivial case of lump-sum transfers available, equity can be reached for any value of $\beta$ and in this case the national government can choose the most efficient allocation of publicly provided production factor without affecting equity.

When lump sum transfers are not available, an increase of equity can only be reached by allocating disproportionate quantities of publicly provided production factor to the disadvantaged region; this will be true until, for very different regions, all publicly provided production factor will be given to the disadvantaged region. The equity maximizing allocation of $P U B, \beta_{e q}$ will therefore be defined as follows (and calculated accordingly):

$$
\beta_{e q}=\left\{\begin{array}{cc}
\operatorname{argmin}_{\beta}\left(\frac{w_{1}(\beta)}{w_{2}(\beta)}-1\right) & \text { if } \operatorname{argmin}_{\beta}\left(\frac{w_{1}(\beta)}{w_{2}(\beta)}-1\right) \subset[0,1] \\
0 & \text { if } \operatorname{argmin}_{\beta}\left(\frac{w_{1}(\beta)}{w_{2}(\beta)}-1\right)<0 \\
1 & \text { if } \operatorname{argmin}_{\beta}\left(\frac{w_{1}(\beta)}{w_{2}(\beta)}-1\right)>1
\end{array}\right.
$$

All the elements needed to study the interplay of equity and efficiency are now available: for different values of the regional parameters we can in fact plot the $\beta^{*}$ and $\beta_{e q}$ and in this way classify the policies depending on the fact that they increase equity and/or efficiency, according to the scheme of Table 2 .

Figure 4 plots the most efficient allocation of $\beta\left(\beta^{*}\right)$ and the most equitable allocation $\left(\beta_{e q}\right)$ when regions differ (from top to bottom) in size $\left(L_{i}\right)$, fixed set-up costs of firms $\left(F_{i}\right)$, and labour productivity $\left(a_{i}\right)$.

On the lefthand side of Figure 4, the graphs are for the easier case of strong agglomeration economies: in this case, the most efficient allocation is, when regions are identical, to give all $P U B$ to one of the two regions or, when regions are different, to give all to the stronger or larger. In the absence of transfers, the most equitable situation is to give more to the weaker region or, when regions are different in size, to give slightly more to the larger.

On the righthand side, there is the case of weak agglomeration economies. In this case, as expected, when regions are identical, the most efficient and the fairest allocations of $P U B$ coincide. However, even in this case of weak agglomeration economies, if the two regions are different, the most efficient allocation is to give more to the region which already holds an advantage, until the differences are strong enough that the most efficient allocation of $P U B$ is again to give all of the public support available to the advantaged region.

The most equitable allocation, on the contrary, is to give a disproportionate quantity of $P U B$ to the weaker region. If regions are different in size, how- 


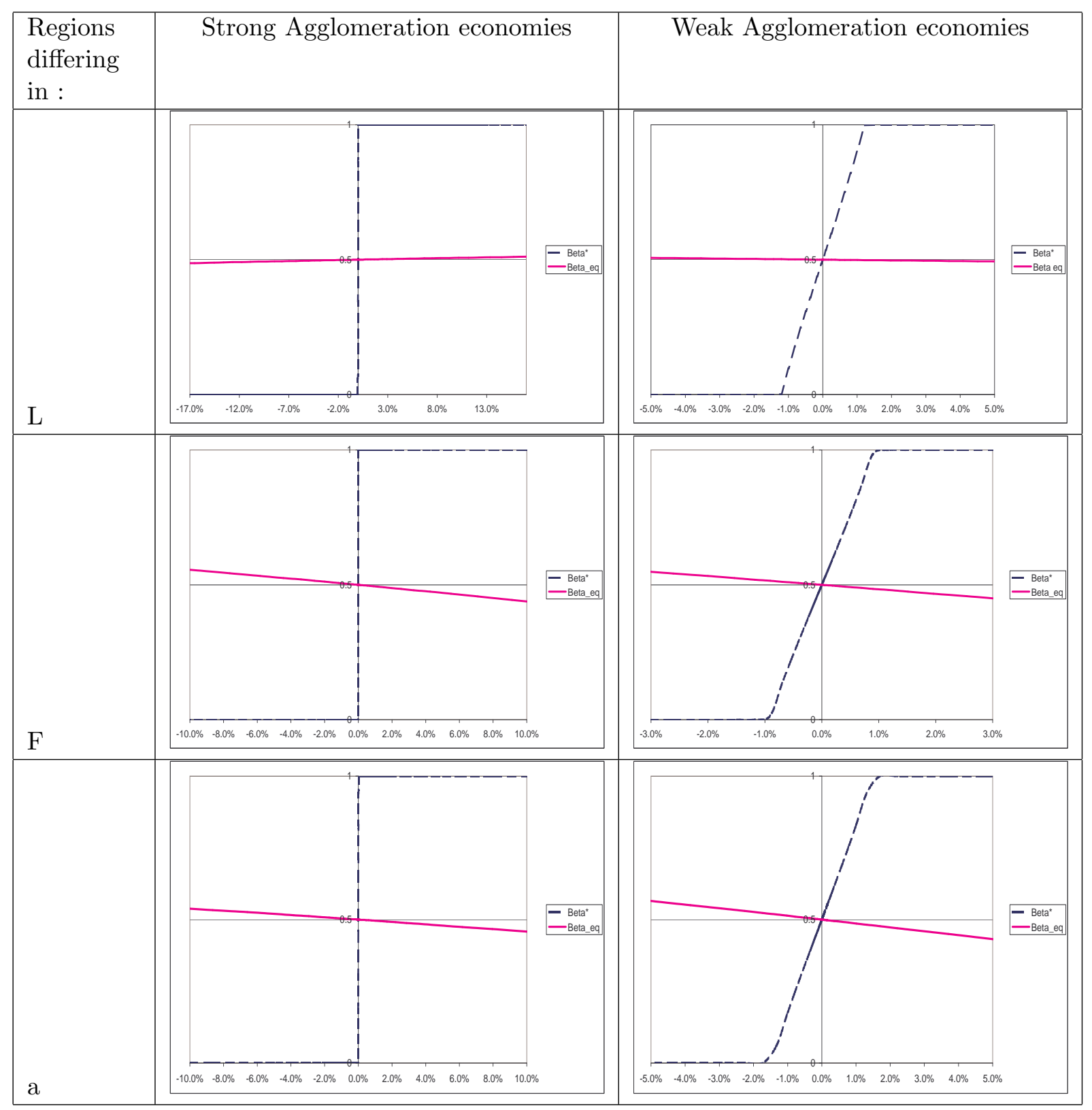

Figure 4: The relationship between regional exogenous characteristics, $\beta^{*}$ and $\beta_{e q}$ in case of strong agglomeration economies (left) and weak agglomeration economies (right): regions differing in size ( $L_{i}$, top), fixed set-up costs $\left(F_{i}\right.$, center $)$ or flexible costs $\left(a_{i}\right.$, bottom). On the horizontal axis the percentage difference between the regions, with a positive value indicating an advantage. 

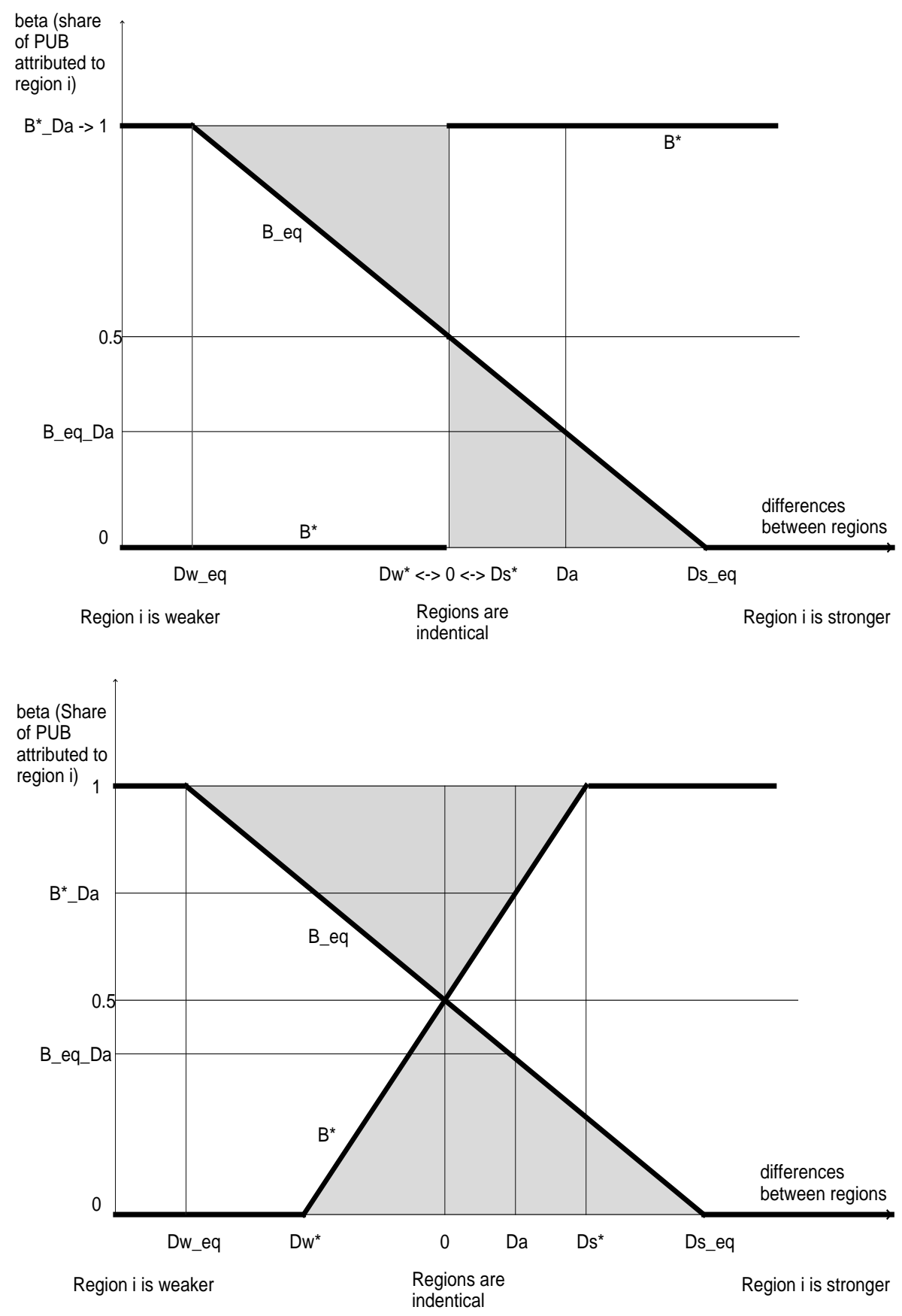

Figure 5: The relationship between $\beta^{*}$ and $\beta_{e q}$ in case of strong agglomeration economies (top) and weak agglomeration economies (bottom). 
ever, it is more equitable to give more to the larger one, since this allows the alleviation of the effects of rivalry in the use of $P U B$.

The interplay of the objectives of equity and efficiency, consistent with the framework of Table 2 and with the results of the model of section 4, can be summarized by a stylized figure (5) that depicts the main features of the actual functions. This figure has on the horizontal axis the (exogenously given) differences between the regions, and on the vertical axis the values of $\beta$.

Depicted on top is the case of strong agglomeration economies. In this case a national policy maker would face a trade-off between equity and efficiency in all cases except when the starting situation of the economy (in terms of $\beta$ and regional structural differences) falls in the shaded area. For instance, if the differences between the regions are at $D_{a}$, the most efficient allocation of $P U B$ is $\beta=1$ (all to region $i$ which is stronger, whereas the most fair allocation is $\beta=\beta_{e q D a}$. If the starting $\beta$ falls in the interval $\left[0, \beta_{\text {eqDa }}\right)$, then there is room for policies improving both equity and efficiency, in the form of an increase of $\beta$. If the starting $\beta$ is above $\beta_{e q D a}$, on the contrary, any policy that modifies the regional allocation of $P U B$ will face a trade-off between an increase of equity and an increase of efficiency.

It is interesting to notice that, when the regions become more different, the fairer allocation of $P U B$ goes towards the weaker region until, for values of differences above $D s^{e q}$ or below $D w^{e q}$ the policy maker always faces a trade-off.

One could imagine that, when agglomeration economies are instead weaker, the trade-off between the objectives of equity and efficiency no longer exist. Actually, as can be seen in the lower part of Figure 5, this is true in this model only if the regions are identical.

As the regions become different, in fact the space of starting allocations of $P U B$ for which there is room for policies improving both equity and efficiency (the shaded area, i.e. the space for which quadrant I policies are possible) decreases. If differences are small, in fact, the trade-off exists when the starting $\beta$ lies between $\beta_{e q D a}$ and $\beta_{D a}^{*}$. As the regions become increasingly different, $\beta_{e q D a}$ and $\beta_{D a}^{*}$ increasingly move away from each other until they become 0 and 1 respectively. If the differences are therefore above $D_{s}^{*}$, there are policies able to combine equity and efficiency only if the starting allocation of $P U B$ is extremely unbalanced towards the weaker region. When differences are also above $D_{s}^{e q}$, on the contrary, whatever the starting allocation, any policy modifying the allocation of $P U B$ will increase equity to the detriment of efficiency, or else increase efficiency to the detriment of equity, i.e the result will be a policy that Table 2 would classify as quadrant VII or quadrant III.

This means that, in a static context, the differences between the regions of which a country is composed are fundamental in determining the 
incompatibility of objectives, thereby incentivating a central government to concentrate the productive expenditure in the advanced region, especially if some sort of compensating transfers are available.

For this reason, a national government facing structural imbalances among the regions of the country, especially if short-sighted, could be induced not to pursue real development policies in the lagging regions, especially if some compensating mechanisms allowing the equity objective to be achieved differently, are available.

This has historically happened in a number of cases; a striking example is the one of the Italian Mezzogiorno, where, in the years of economic boom for the country, the South gained much more in terms of ability to consume than in productive capability. After the "Autunno Caldo" of 1969 (Boltho et al., 1997) the nominal wages became more similar across the country and, added to the standing gap in infrastructures and services (Confindustria, 2000) this contributed to the lack of inward investment.

What is remarkable, though, is that the movements of population from south to north have nearly halted after the mid-70's, and this is despite the huge difference in unemployment rates. Attanasio and Padoa Schioppa (1991) found five separate and additional causes that increase the cost of moving: the fact that women are now in the labour market in large numbers makes it more difficult for men to relocate because of the need to find two jobs instead of one; the differences in the prices of basic facilities, especially housing; labour laws that make firing and hiring very difficult; the aggregate unemployment rate that may affect the gains from migration; and, finally, even the fact that after some years of low migration mobility itself is more difficult, possibly because of the loosening of ties deemed useful to relocate. More relevant for the analysis of this paper, in addition to increasing costs, two other causes for the drop in migration are identified: the decrease in interregional real wage differentials and the rise in the government transfers to the south, that allows the so-called "wait unemployment" of young people who can rely on family support ${ }^{4}$.

As Lombardini (1992) points out, in Italy, an efficient industrial policy has never been set up, instead all the policies have been developed in an assistantial manner, indeed the southern regions have developed only as a big market for the north's products. The hoped-for movements of northern entrepreneurs to the south did not occur in the 50's and 60's, when the labour cost in the south still was consistently lower than in the north, because of the lack of reliability of the public administrations in granting

\footnotetext{
${ }^{4}$ Faini et al. (1997), however, criticise this last point and find that higher household income makes it easier to finance the cost of migration; their favorite explanation is a combination of demographic factors, high mobility costs and a job searching process that in Italy is highly inefficient.
} 
basic services, infrastructures and even security from crime. Instead, many skilled southerners have moved northwards together with an unskilled workforce that contributed with cheap labour to the "Italian Miracle" of these decades.

Today the GDP of the south is around $54 \%$ of the one of the north's but consumption is much more even at the national level, since the southern value is about at $72 \%$ of the northern's.

This development pattern has always been interpreted negatively by all commenters, for example Alesina et al. (1999) measured that half of the public wage bill in the south can be defined as a subsidy, given the size of public employment and the wage premium for public jobs with respect to private ones. They also find that this form of subsidy has very negative effects, since it creates a dependency equilibrium in which private jobs are not attractive, thereby making it difficult for an entrepreneur to offer wages competitive with those offered in the public administrations.

Some similarities (but also some differences) exist with East-Germany case: according to Boltho et al. (1997), after re-unification, former DDR has experienced a high raise in nominal wages (from $10 \%$ to $70 \%$ of Western Germany) and transfers, but the outcomes should be different from the Italian case since wage differentials remain consistent enough for competitiveness, the investment rate is very high and, very importantly, East Germany has a tradition of entrepreneurship (it was the most advanced part of the country before WWII) and prosperity; these attributes are seen to give East Germans the opportunity to avoid becoming entangled in dependency and subsidy-seeking behaviours.

Sinn and Westermann (2001) find, in addition to striking similarities in terms of artificially low wage differential, dependency on transfers and locational disadvantages, that the level of investment in East Germany is decreasing, that wages are still higher than productivity and even that "it is impossible to run a market economy where the minimum income guaranteed through the welfare system is equal to the average net-of-tax wage income" (Sinn and Westermann, 2001, p. 23). As a consequence, the process of convergence between the two Germanys, substantial until 1996, had halted by 1997. The solutions they propose are decentralised wage bargaining, a leaner welfare state to avoid the crowding out of the private labour market, and transfers through infrastructure investment instead of social support.

This paper is too short to include a direct investigation of the Italian, German or other real-world cases; however, the model of section 4 has shown theoretically that concentrating productive investment in the most advanced region can be the most efficient choice in the short run.

Therefore, especially if some sort of compensating mechanisms are available, a short-sighted policy-maker running a country in which some regions are more productive than others, would find it convenient to further the production in the already highly-productive regions in order to produce the 
maximum of resources nationally, and then redistribute income to the lagging regions under the form of consumption subsidies.

\section{Conclusions}

This paper has addressed the issue of the compatibility of the two possibly separated objectives of national economic efficiency and interregional equity within a framework of regional policy. It has done so with a new twocountry four-region model in which agglomeration economies are explicitly modelled together with a policy of support to entrepreneurship that can be differentiated between the regions of a country.

The model is static and describes the short-run situation of many economies, where factor mobility is low and structural differences cannot be adjusted rapidly. The model proves to be very easy to use to study what may be the trade-offs between equity and efficiency if the country is composed of different regions.

If the regions composing a country are identical, the model behaves as the bulk of the literature predicts: for strong agglomeration economies, the most efficient policy is to support entrepreneurship in just one region, when agglomeration economies are lower it is efficient to divide the public productive support equally among the two regions. If transfers of income are not available, the most equitable policy is always to give the same to both.

When the regions are differently productive, though, the most intuitive and diffused result is controverted. Equity is still achieved with more support to the less advanced region. Efficiency, on the contrary, is achieved differently from the previous case: when agglomeration economies are strong, the optimal policy is to concentrate all support in the most advanced region, but also when agglomeration economies are weak, if the regions are different, it is efficient to give an increased quota of support to the most advanced region until, as regional differences become sufficiently wide, it becomes efficient to concentrate all public support in the most productive region, exactly as with strong agglomeration economies.

This behaviour bears striking similarities to two real world cases, as evidenced in the last section of the paper.

The model leaves open the possibility that policies concentrating the productive support in the already stronger region, with some income compensation for the poorer, could, despite being efficient in the short-run, be detrimental to long-run growth.

However, a short-sighted policy-maker is not necessarily irrational or malevolent: political (e.g. national cohesion) and social (e.g. welfare differentials or unemployment) factors can play an important role and make it preferable to sacrifice some future growth for short-run GDP. And in the short-run, as this paper has shown, when countries are composed of sufficiently differ- 
ent regions, there always exists a trade-off between interregional equity and national efficiency, unless transfers are available, in which case the best national policy is to concentrate the support to entrepreneurship in the most advanced regions and compensate the lagging ones with income transfers.

\section{References}

A. Alesina, S. Danninger, and M. V. Rostagno. Redistribution through public employment: The case of italy. NBER Working Paper, (7387), 1999.

O. Attanasio and F. Padoa Schioppa. Regional inequalities, migration and mismatch in italy, 1960-1986. In O. Attanasio and F. Padoa Schioppa, editors, Mismatch and Labour mobility. Cambridge University Press, Cambridge, 1991.

R. E. Baldwin. The Core-Periphery model with forward looking expectations. Regional Science and Urban Economics, (31):21-49, 2001.

R. E. Baldwin, R. Forslid, P. Martin, G. Ottaviano, and F. Robert-Nicoud. Economic Geography and Public Policy. Princeton University Press, 2003.

K. Behrens. Agglomeration without trade: how non traded goods shape the space-economy. Journal of Urban Economics, 55:68-92, 2004.

M. Berliant and T. ben Raa. Increasing returns and perfect competition: the role of land. Journal of Urban Economics, 56:97-118, 2004.

K. Bjorvatan and G. Schjelderup. Tax competition and international public goods. International tax and public finance, 9:111-120, 2002.

A. Boltho, W. Carlin, and P. Scaramozzino. Will east germany become a new mezzogiorno? Journal of Comparative Economics, (24):241-264, 1997.

M. Chui, P. Levine, S. Mansoob Murshed, and J. Pearlman. North-south models of growht and trade. Journal of Economic Surveys, 16(2):123-165, 2002 .

EU Commission. A new partnership for cohesion: convergence competitiveness cooperation. third report on economic and social cohesion, 2004.

Confindustria. La dotazione infrastrutturale delle province italiane. Confindustria, Roma, 2000.

D. Darwent. Growth poles and growth centers in regional planning - a review. Environment and Planning, 1:5-32, 1969. 
S. Davies and M. Hallet. Interactions between national and regional development. HWWA Discussion Paper, (207), 2002.

A. K. Dixit and J. E. Stiglitz. Monopolistic competition and optimum product diversity. The American Economic Review, 67(3):297-308, 1977.

V. Dupont and P. Martin. Subsidies to poor regions and inequalities: some unpleasant arithmetic. CEPR Discussion Papers, (3620), 2003.

R. Faini, G. Galli, P. Gennari, and F. Rossi. An empirical puzzle: falling migration and growing unemployment differentials among italian regions. European Economic Review, 41:571-579, 1997.

M. Fujita, P. Krugman, and P. Venables. The Spatial Economy: cities, regions and international trade. The MIT Press, 1999.

M. Fujita and J. F. Thisse. Economics of Agglomeration; Cities, Industrial Location and Regional Growth. Cambridge University Press, 2002.

G. M. Grossman and E. Helpman. Quality ladders in the theory of growth. Review of Economic Studies, 58(1):43-61, 1991.

B. Higgins. Regional development and efficiency of the national economy. In B. Higgins and D. J. Savoie, editors, Regional Economic Develoopment, Essays in honour of Francois Perroux, pages 193-224. Unwin Hyman, 1988.

C. Hurst, J.-F. Thisse, and P. Vanhoudt. What diagnosis for europe's ailing regions? EIB Papers, 5(1):9-30, 2000.

M. Justman, J.-F. Thisse, and T. van Ypersele. Taking the bite out of fiscal competition. CEPR Discussion Papers, (3109), 2001.

P. Krugman. Geography and Trade. The MIT Press, 1991a.

P. Krugman. Increasing Returns and Economic Geography. The Journal of Political Economy, 99(3):483-499, 1991b.

L. F. Lanaspa, F. Pueyo, and F. Sanz. The public sector and the coreperiphery model. Urban Studies, 38(10):1639-1649, 2001.

L. F. Lanaspa and F. Sanz. Regional policy and industrial location decisions. Urban Studies, 36(3):499-507, 1999.

L. F. Lanaspa and F. Sanz. Multiple equilibria, stability and asymmetries in krugman's core-periphery model. Papers in Regional Science, 80:425-438, 2001.

L. F. Lanaspa and F. Sanz. Regional policy and industrial location decisions. Investigaciones Economicas, XXVIII(I):67-87, 2004. 
J. Leach. Training, migration and regional income disparities. Journal of Public Economics, 61:429-443, 1996.

S. Lombardini. Vecchi e nuovi problemi al sud. In M. D'Antonio, editor, Il Mezzogiorno D'Italia: Sviluppo o Stagnazione? Il Mulino, Bologna, 1992.

R. D. Ludema and I Wooton. Economic geography and the effects of regional integration. Journal of International Economics, 52:331-357, 2000.

A. Markusenn. Interaction between regional and industrial policies: Evidence from four countries. International Regional Science Review, 19 (1-2):49-77, 1996.

P. Martin. Can regional policies affect growth and geography in europe? The World Economy, 21:757-774, 1998a.

P. Martin. Are european regional policies delivering? EIB Papers, 4(2): 10-23, 1999a.

P. Martin. Public policies, regional inequalities and growth. Journal of Public Economics, 73(1):85-105, 1999b.

P. Martin. The role of public policy in the process of regional convergence. EIB Papers, 5(2):69-79, 2000.

P. Martin and G. I. P. Ottaviano. Growing locations: Industry location in a model of endogenous growth. CEPR Discussion Papers, (1523), 1996.

P. Martin and G. I. P. Ottaviano. Growing locations: Industry location in a model of endogenous growth. European Economic Review, 43:281-302, 1999.

P. Martin and C. A. Rogers. Industrial location and public infrastructure. Journal of International Economics, 39(3-4):152-166, 1995.

R. Martin. The new 'geographical turn' in economics: Some critical reflections. Cambridge Journal of Economics, 1998b.

P. Maystadt. Preface. EIB Papers, 5(1):4-6, 2000.

G. Mion. Spatial extrernalities and empirical analysis: the case of italy. Journal of Urban Economics, 56:97-118, 2004.

Y. Murata. Priduct diversity, taste heteroeneity and geographic distribution of economic activities: market vs non-market interactions. Journal of Urban Economics, 53:126-144, 2003.

J. P. Neary. Competition, Trade and Wages. Mimeo, University College Dublin, 2001. 
G. I. P. Ottaviano. Ad usum delphini: A primer in new economic geography. EUI Working Paper in Economics, (No.28/99), 1999.

G. I. P. Ottaviano. Monopolistic competition, trade, and endogenous spatial fluctuations . Regional Science and Urban Economics, 31:51-77, 2001.

G. I. P. Ottaviano. Regional policy in the global economy. Regional Studies, 37(7-7):665-673, 2003.

G. I. P. Ottaviano and D. Puga. Agglomeration in the global economy: A survey of new economic geography. World Economy, 21:707-731, 1998.

G. I. P. Ottaviano, T. Tabuchi, and J.-F. Thisse. Agglomeration and trade revisited. International Economic Review, 43(2):409-435, May 2002.

G. I. P. Ottaviano and J.-F. Thisse. Integration, agglomeration and the political economics of factor mobility. Journal of Public Economics, 83: 429-456, 2002.

G. I. P. Ottaviano and J.-F. Thisse. Agglomeration and economic geography. CEPR Discussion Papers, (3838), 2003.

D. Puga. European regional policies in light of recent location theories. Journal of Economic Geography, 2(4):373-406, 2002.

H.-W. Sinn and F. Westermann. Two mezzogiornos. NBER Working Paper, (8125), 2001.

R. M. Solow. A contribution to the theory of economic growth. Quarterly Journal of Economics, 70(1):65-94, 1956.

D. Starrett. Market allocations of locational choice in a model with free mobility. Journal of Economic Theory, 17:21-37, 1978.

J-F. Thisse. Agglomeration and regional imbalance: Why? and is it bad. EIB Papers, 5(2):47-67, 2000.

N. Vanhove. Regional Policy: a European Approach. Ashgate, 1999.

R. W. Wickerman. Regions' infrastructure in a region's development. In R. W. Wickerman, editor, Infrastructure and Regional Development. Pion, London, 1991.

D. E. Wildasin. Fiscal competition in space and time. Journal of Public Economics, 87:2571-2588, 2003. 